\title{
Factors associated with willingness to take extended release naltrexone among injection drug users
}

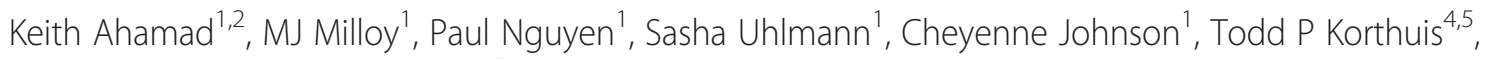
Thomas Kerr ${ }^{1}$ and Evan Wood ${ }^{1,3,6^{*}}$

\begin{abstract}
Background: Although opioid-agonist therapy with methadone or buprenorphine/naloxone is currently the mainstay of medical treatment for opioid use disorder, these medications often are not well accepted or tolerated by patients. Recently, extended release naltrexone (XR-NTX), an opioid antagonist, has been advanced as an alternative treatment. The willingness of opioid-addicted patients to take XR-NTX has not been well described.
\end{abstract}

Methods: Opioid-using persons enrolled in a community-recruited cohort in Vancouver, Canada, were asked whether or not they would be willing to take XR-NTX. Logistic regression was used to independently identify factors associated with willingness to take the medication.

Results: Among the 657 participants surveyed between June 1, 2013, and November 30, 2013, 342 (52.1\%) were willing to take XR-NTX. One factor positively associated with willingness was daily heroin injection (adjusted odds ratio [AOR] = $1.53 ; 95 \%$ confidence interval $[\mathrm{Cl}]=1.02-2.31$ ), whereas Caucasian ethnicity was negatively associated $(\mathrm{AOR}=0.59 ; 95 \%$ $\mathrm{Cl}=0.43-0.82)$. Satisfaction with agonist therapy (13.4\%) and unwillingness to stop opioids being used for pain (26.9\%) were the most common reasons for being unwilling to take XR-NTX.

Conclusions: A high level of willingness to take XR-NTX was observed in this setting. Interestingly, daily injection heroin use was positively associated with willingness, whereas Caucasian participants were less willing to take XR-NTX. Although explanations for unwillingness were described in this study, further research is needed to investigate real-world acceptability of XR-NTX as an additional option for the treatment of opioid use disorder.

Keywords: Addiction, Willingness to take, Opioid antagonist

\section{Background}

Opioid use disorder remains a major public health concern worldwide. Globally, opioids top the list of illicit drugs that cause substantial morbidity and mortality [1]. In the United States alone, over 5 million people abused prescription pain relievers in 2010 [2]. Nonmedical users of prescription opioids have also been shown to be almost 8 times more likely to use heroin and over 4 times more likely to use intravenously [3].

\footnotetext{
* Correspondence: uhri-ew@cfenet.ubc.ca

'British Columbia Centre for Excellence in HIV/AIDS, St. Paul's Hospital, 1081

Burrard Street, Vancouver, BC V6Z 1Y6, Canada

${ }^{3}$ Department of Medicine, University of British Columbia, 10th Floor 2775

Laurel Street, Vancouver, BC V5Z 1M9, Canada

Full list of author information is available at the end of the article
}

While the health and social consequences of opioid use disorder are well documented, past studies have clearly demonstrated significant reductions in these consequences through medically assisted treatment with methadone or buprenorphine, which are the gold standards for medical management of opioid use disorder [4-7]. In terms of psychosocial treatments, past studies have generally shown that without opioid-agonist medications like methadone or buprenorphine, the vast majority of patients will be treatment-refractory to psychosocial and nonpharmacological interventions $[4,8]$.

Unfortunately, due to the real or perceived side effects or programmatic characteristics, treatment with methadone and buprenorphine does not attract all users into treatment. Commonly reported barriers to program 
entry include limited treatment availability, the high threshold of treatment programs (i.e., safe dose titration timelines), and requirements that opioid-agonist medications must be provided via daily, witnessed ingestion [9]. Furthermore, while they vary from setting to setting, retention rates with opioid-agonist treatments are only approximately 60 percent, and many patients on methadone or buprenorphine should remain on this medication indefinitely [10-12]. Oral naltrexone, an opioid-receptor antagonist, has been proposed as an alternative for patients. Naltrexone has several advantages in that it has few drug-drug interactions, no physical dependence, and a favorable side-effect profile [13]. Unfortunately, due to the requirement for daily oral dosing, medication adherence has been the major barrier to its efficacy [14].

Recently, naltrexone for extended-release injectable suspension (XR-NTX), which is administered via intramuscular injection every 4 weeks, has been advanced as an alternative treatment $[15,16]$. Placebo-controlled trials have demonstrated its efficacy in retaining patients in treatment, increasing abstinence, and decreasing opioid cravings [15-17]. However, it has recently been noted that the willingness of opioid-addicted patients to take XR-NTX has not been well described [18]. Since little is known about the willingness of opioid-addicted patients to take an extended-release, opioid-antagonist medication (or about factors that may predict willingness), we undertook this study to examine the willingness to use XR-NTX among opioid-addicted patients participating in a cohort study in Vancouver, Canada.

\section{Methods}

Data for this study were derived from the Vancouver Injection Drug Users Study (VIDUS), an open, prospective cohort of HIV-seronegative individuals who inject drugs, and the AIDS Care Cohort to Evaluate Access to Survival Services (ACCESS), an open, prospective cohort of HIVseropositive individuals who use illicit drugs in Vancouver, Canada. Detailed methodology has previously been described $[19,20]$. Participants were eligible for the study if they were 18 years or older, used illicit drugs other than cannabis within the past month, resided in the Greater Vancouver region, and provided informed consent. Participants were recruited through extensive street-based outreach methods and snowball sampling, beginning in May 1996. At baseline and every 6 months thereafter, participants completed an interviewer-administered questionnaire that elicited information regarding sociodemographic characteristics, drug use, HIV risk behaviors, and treatment utilization, and underwent an examination by a nurse. Participants received a \$20 CAD stipend for each visit. VIDUS and ACCESS study recruitment and follow-up procedures were essentially identical, with the exception of questions specific to HIV infection, to enable merged analyses. Both the VIDUS and ACCESS studies were ethically approved by the Research Ethics Board of Providence Health Care/ University of British Columbia.

For the primary analysis, we restricted the study sample to those who reported any use of opioids or who enrolled in methadone maintenance therapy in the past 6 months, and assessed whether participants were willing to take XR-NTX for opioid addiction treatment by adding questions to follow-up visits between June 1, 2013, and November 30, 2013. Specifically, participants were asked: "There is a new medication that can be given to people who have detoxed from heroin or other opioids, including methadone. It is given by intramuscular injection. It completely blocks the effects of opioids, including pain medications, for 30 days. If you are on methadone or using other opioid drugs, would you be interested in taking this medication if it becomes available in Canada?" Since XR-NTX was not available in Canada at the time these questions were utilized, staff were trained to answer questions about the medication's effects, induction, and duration of action. Participants who answered "Yes" were compared to those who answered "No" on a variety of a priori-selected sociodemographic, behavioral, and drug use variables hypothesized to be associated with willingness to take XR-NTX.

These variables included: age (per year older); female gender (yes vs. no); ethnicity (Caucasian vs. other); daily heroin injection (yes vs. no); daily cocaine injection (yes vs. no); daily crack smoking (yes vs. no); homelessness (yes vs. no); involvement in sex work, defined as exchanging sex for money, gifts, food, shelter, clothes, drugs, or other commodities (yes vs. no); HIV seropositivity (yes vs. no); or participation in drug treatment, defined as alcohol and/or drug treatment other than methadone treatment (yes vs. no). All behavioral and drug use characteristics refer to the 6-month period prior to the interview. All variable definitions have been used extensively and were identical to earlier publications [21,22].

We used bivariate and multivariate logistic regression analyses to determine factors associated with the willingness to take XR-NTX. To identify the independent correlates of willingness to take XR-NTX, only variables that were associated with willingness at $p$-value $<0.10$ in bivariate analyses were considered in the full multivariate model. Using the backwards-selection procedure, we constructed the final multivariate model with the best fit, as indicated by the lowest Akaike Information Criterion (AIC) value.

As a sub-analysis among participants who did not report any willingness to take XR-NTX, their reasons from the subsequent question were collated. Participants could select more than one response from the following reasons: "Not using opioids"; "happy with methadone/suboxone (buprenorphine/naloxone)"; "don't feel that I could detox 
from opioid use or reduce my methadone to zero"; "feel I could not get off my pain med"; "don't want to take a long-acting medication by injection"; and "other". All statistical analyses were performed using SAS software version 9.3 (SAS, Cary, NC, USA). All statistical tests were two-sided, with alpha $=0.05$.

\section{Results}

Between June 1, 2013, and November 30, 2013, 657 opioid-using VIDUS and ACCESS participants were interviewed and included in the present analysis. Among these individuals, median age was 48 (inter-quartile range $=41-53) ; 249(37.9 \%)$ were female; and 397 (60.4\%) were Caucasian (Table 1).

Of the 657 participants, 342 (52.1\%) indicated a willingness to take XR-NTX. As shown in Table 1, the sociodemographic, behavioral, and drug use characteristics associated with a willingness to take XR-NTX in unadjusted analyses included: age, female gender, daily heroin injection, and Caucasian ethnicity (all $p<0.05$ ). The results of the multivariate analysis are presented in Table 2. Factors independently associated with a willingness to take XR-NTX included: daily heroin injection (adjusted odds ratio $[A O R]=1.53 ; 95 \%$ confidence

Table 1 Characteristics of study participants assessed for willingness to take an opioid antagonist $(\mathrm{N}=657)$

\begin{tabular}{|c|c|c|c|c|}
\hline \multirow[t]{2}{*}{ Characteristic } & \multicolumn{2}{|l|}{ Willingness } & \multirow{2}{*}{$\begin{array}{l}\text { Odds ratio } \\
\left(95 \% \mathrm{Cl}^{\mp}\right)\end{array}$} & \multirow[t]{2}{*}{$p$ value } \\
\hline & $\mathrm{No}=315(\%)$ & Yes $=342(\%)$ & & \\
\hline Age [Median, $\left.\left(\mathrm{IQR}^{\mp}\right)\right]$ & $49(41-54)$ & $46(40-51)$ & $0.98(0.96-1.00)$ & 0.015 \\
\hline \multicolumn{5}{|l|}{ Gender } \\
\hline Male & $209(66.3)$ & $199(58.2)$ & & \\
\hline Female & $106(33.7)$ & $143(41.8)$ & $1.42(1.03-1.95)$ & 0.032 \\
\hline \multicolumn{5}{|l|}{ Caucasian ethnicity } \\
\hline No & $102(32.4)$ & $158(46.2)$ & & \\
\hline Yes & $213(67.6)$ & $184(53.8)$ & $0.56(0.41-0.77)$ & $<0.001$ \\
\hline \multicolumn{5}{|l|}{ Daily heroin injection* } \\
\hline No & $268(85.1)$ & $270(79.0)$ & & \\
\hline Yes & $47(14.9)$ & $71(20.8)$ & $1.50(1.00-2.25)$ & 0.050 \\
\hline \multicolumn{5}{|c|}{ Daily cocaine injection* } \\
\hline No & $289(91.7)$ & $319(93.3)$ & & \\
\hline Yes & $26(8.3)$ & $23(6.7)$ & $0.80(0.45-1.44)$ & 0.457 \\
\hline \multicolumn{5}{|l|}{ Daily crack smoking* } \\
\hline No & $251(79.7)$ & 279 (81.6) & & \\
\hline Yes & $64(20.3)$ & $63(18.4)$ & $0.89(0.60-1.30)$ & 0.538 \\
\hline \multicolumn{5}{|l|}{ Homelessness* } \\
\hline No & $273(86.7)$ & $295(86.3)$ & & \\
\hline Yes & $42(13.3)$ & $46(13.5)$ & $1.01(0.65-1.59)$ & 0.953 \\
\hline \multicolumn{5}{|l|}{ Sex work* } \\
\hline No & $293(93.0)$ & $312(91.2)$ & & \\
\hline Yes & $22(7.0)$ & $30(8.8)$ & $1.28(0.72-2.27)$ & 0.397 \\
\hline \multicolumn{5}{|l|}{ HIV positive } \\
\hline No & $189(60.0)$ & $198(57.9)$ & & \\
\hline Yes & $126(40.0)$ & $144(42.1)$ & $1.09(0.80-1.49)$ & 0.584 \\
\hline \multicolumn{5}{|c|}{ Participation in drug treatment ${ }^{* *}$} \\
\hline No & $257(81.6)$ & $275(80.4)$ & & \\
\hline Yes & $57(18.1)$ & $64(18.7)$ & $1.05(0.71-1.56)$ & 0.812 \\
\hline
\end{tabular}

NOTE: Percentages do not necessarily sum to $100 \%$ due to missing data or rounding error.

*Activities in last 6 months.

**Defined as drug and/or alcohol treatment other than a methadone program.

${ }^{\sharp} \mathrm{IQR}=$ inter-quartile range.

${ }^{\mathbf{E}} \mathrm{Cl}=$ confidence interval. 
Table 2 Multivariate analysis of factors associated with the willingness to take an opioid antagonist $(\mathrm{N}=657)$

\begin{tabular}{llll}
\hline Characteristic & Adjusted odds ratio & $\mathbf{9 5 \%} \mathbf{C l}^{\mathbf{⿷}}$ & $\boldsymbol{p}$ value \\
\hline $\begin{array}{l}\text { Daily heroin injection* } \\
\text { Yes vs. No }\end{array}$ & 1.53 & $1.02-2.31$ & 0.043 \\
$\begin{array}{l}\text { Female gender } \\
\text { Yes vs. No }\end{array}$ & 1.29 & $0.93-1.79$ & 0.133 \\
$\begin{array}{l}\text { Caucasian ethnicity } \\
\text { Yes vs. No }\end{array}$ & 0.59 & $0.43-0.82$ & 0.002 \\
\hline
\end{tabular}

${ }^{\mathbf{E}} \mathrm{Cl}=$ confidence interval.

*Activities in last 6 months.

interval $[\mathrm{CI}]=1.02-2.31)$; and Caucasian ethnicity $(\mathrm{AOR}=0.59 ; 95 \% \mathrm{CI}=0.43-0.82])$.

As shown in Figure 1, of the 315 (47.9\%) participants who indicated that they would not be willing to take XR-NTX, 320 reasons were given for unwillingness and included: 53 (16.6\%) reported that they were not actively taking opioids; 43 (13.4\%) were happy with methadone/ suboxone (buprenorphine/naloxone); 25 (7.8\%) didn't feel that they could detox from opioids; 86 (26.9\%) didn't feel that they could get off pain medications; 7 (2.2\%) didn't want to take a long-acting medication by injection; $9(2.8 \%)$ reported concern regarding untreated pain if injured; 23 (7.2\%) reported they liked using heroin; 11 (3.4\%) reported needing more information; and 63
(19.7\%) reported a variety of other reasons that were not consistent enough to be collapsed into categories. Data are available from the corresponding author.

\section{Discussion}

In the present study, we found high rates of willingness to take XR-NTX among a community-recruited cohort of opioid drug users. We also found that daily heroin use was independently associated with a higher likelihood of willingness to take XR-NTX, whereas Caucasian participants were associated with a lower likelihood of willingness. Among the reasons reported for unwillingness to take XR-NTX: a) the perceived inability to stop opioid use for pain, and b) satisfaction with methadone/ buprenorphine were the most frequently cited reasons.

This is the first study, to our knowledge, to assess patients' interest in taking a long-acting opioid antagonist for the treatment of opioid addiction. Rather than patient-related factors, past studies have examined how individual and organizational variables can influence treatment program attitudes towards use of medications for the treatment of opioid addiction [23]. Fuller et al. (2005) surveyed outpatient substance abuse treatment centers and found that standalone substance abuse clinics were less likely to provide naltrexone [24]. Past studies have also examined adoption of naltrexone in the context of alcohol use disorder and found that only

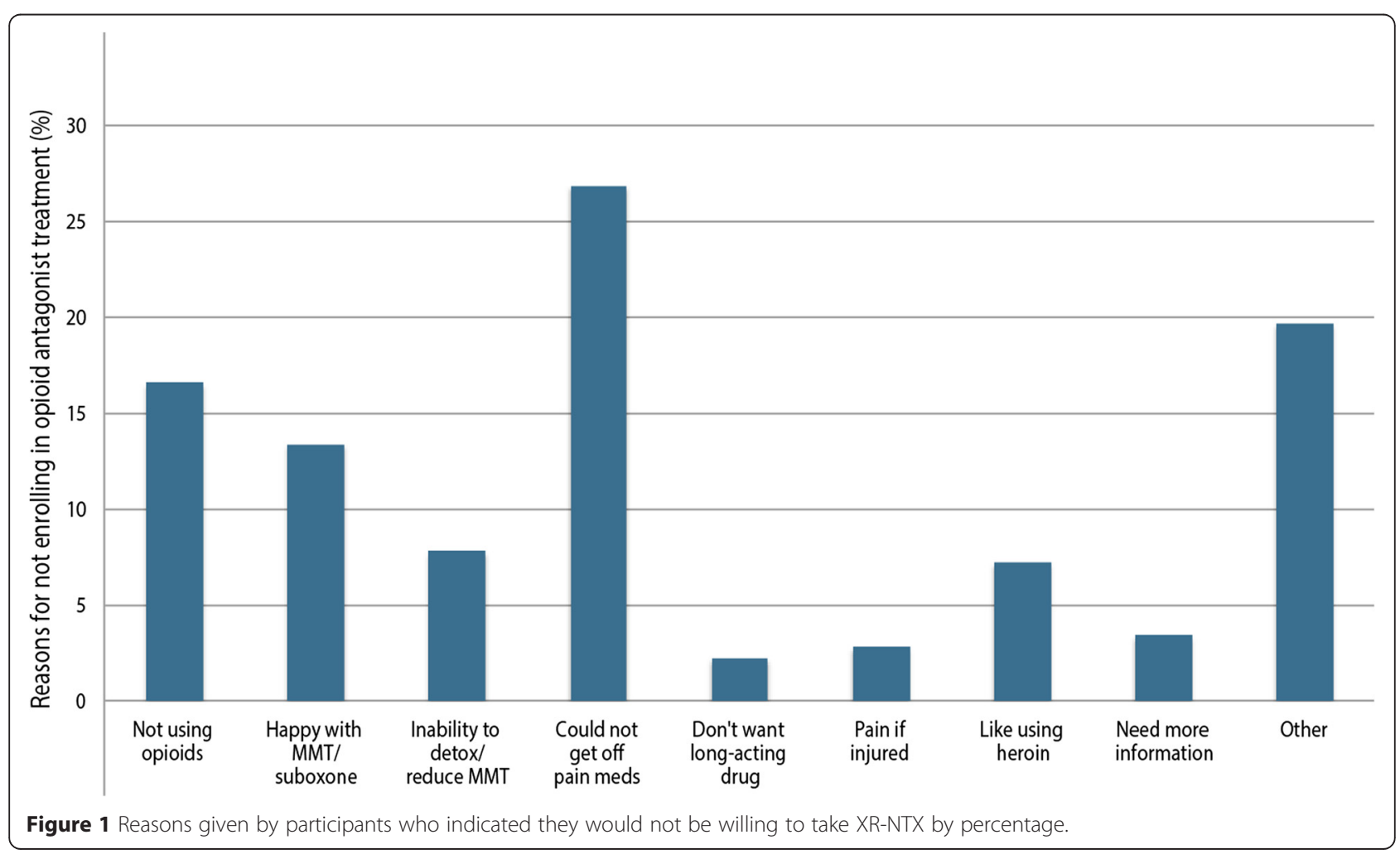


15 percent of alcohol treatment clinicians prescribe naltrexone often [25]. In light of the dearth of information regarding patient profiles that may be appropriate for XR-NTX, Ling et al. outlined some of the questions regarding the role of XR-NTX in opioid dependence, including the fact that "no one seems to have figured out that perhaps we should ask our patients whether they would like to take [XR-NTX]" [18].

Our findings show a high degree of willingness to take XR-NTX, particularly among high-intensity heroin injectors. These results show there is a subset of opioid users who are willing to try alternatives to traditional opioid-agonist therapy. This may represent the fact that methadone has very high penetrance in Vancouver, and that those who have had a longstanding opportunity to engage in methadone treatment remain hesitant to take this medication for programmatic reasons (e.g., daily witness ingestion) and may be interested in an alternative [26]. Importantly, Kerr et al. showed in 2005 that opioid-injecting Aboriginal patients were less than half as likely to use methadone maintenance than nonAboriginal persons [26]. In this regard, it is noteworthy that the majority of individuals in the non-Caucasian category in the present study were Aboriginal. While preliminary, our results suggest that there are likely reasons for the unwillingness to take opioid-agonist treatment that are more prevalent among Aboriginal persons, whereas this population may be more open to alternatives, including XR-NTX [26]. This is an issue that will require further study, potentially using qualitative research methods to explore this question and to examine willingness and unwillingness to take XR-NTX.

This study has limitations. As our study sample was generated through street-based recruitment methods, generalizing our findings to other populations of injection drug users requires caution. However, it is noteworthy that the cohort demographics are similar to other local and international studies of drug users [27-30]. Secondly, as our outcome of interest was willingness to take XR-NTX, actual rates of willingness and successful induction onto XR-NTX will need to be studied in clinical trials in realworld settings. In particular, all elements of the medications' benefits and side-effect profile could not be fully described in the context of our study. In this regard, assessment of specific populations, including HIV-infected individuals, is the subject of ongoing investigation, as can be seen with the National Institute on Drug Abuse (NIDA) Clinical Trials Network (CTN) 055 CHOICES study [31]. Finally, socially desirable responding is a concern in studies of marginalized populations [32]. Although interviewers were trained to build trust and rapport with participants, and confidentiality was assured, it is possible we overestimated the percentage of individuals willing to participate as a result of this concern.
In summary, the present study found high rates of willingness to take XR-NTX in this setting. Interestingly, daily injection heroin use was independently and positively associated with willingness to take XR-NTX, while Caucasian participants were negatively associated with this choice, suggesting that sub-populations may benefit from this medication. Although patient-reported explanations for unwillingness were described in this study, including satisfaction with agonist therapy and concerns regarding stopping opioid-based pain medications, further research is needed to investigate real-world acceptability of XR-NTX as an additional option for the treatment of opioid use disorder.

\section{Competing interests}

The authors declare that they have no competing interests.

\section{Authors' contributions}

KA interpreted analyses and wrote large portions of the manuscript. EW conceived the study, participated in its design and coordination, and helped draft the manuscript. PN conducted the statistical analyses and aided in the interpretation of analyses. SU, MJM, CJ, TK, and PTK were involved in revising the manuscript. Each author has approved of the final version of this manuscript.

\section{Acknowledgements}

The authors thank the study participants for their contributions to the research, as well as current and past researchers and staff. We would specifically like to thank: Peter Vann, Kristie Starr, Deborah Graham, Tricia Collingham, Carmen Rock, Jennifer Matthews, Steve Kain, Benita Yip, and Guillaume Colley for their research and administrative assistance. The study is supported by research funds from the U.S. National Institutes of Health (NIH): VIDUS (R01DA011591) and ACCESS (R01DA021525). This research was undertaken, in part, thanks to funding for a Tier 1 Canada Research Chair in Inner City Medicine, which supports Dr. Evan Wood. Dr. Milloy is supported in part by $\mathrm{NIH}$. Dr. Korthuis' and Dr. Wood's participation was supported by NIDA CTN U10 DA015815.

\section{Author details}

${ }^{1}$ British Columbia Centre for Excellence in HIV/AIDS, St. Paul's Hospital, 1081 Burrard Street, Vancouver, BC V6Z 1Y6, Canada. ²Department of Family Practice, University of British Columbia, 5950 University Boulevard Street, Vancouver, BC V6T 1Z3, Canada. ${ }^{3}$ Department of Medicine, University of British Columbia, 10th Floor 2775 Laurel Street, Vancouver, BC V5Z 1M9, Canada. ${ }^{4}$ Department of Medicine, Oregon Health and Science University, 3181 SW Sam Jackson Park Rd, Portland, OR 97239, USA. 'Department of Public Health-Preventive Medicine, Oregon Health and Science University, 3181 SW Sam Jackson Park Rd, Portland, OR 97239, USA. ${ }^{6}$ Division of Epidemiology and Population Health, BC Centre for Excellence in HIV/AIDS, 608-1081 Burrard Street, Vancouver, BC V6Z 1Y6, Canada.

Received: 23 October 2014 Accepted: 23 April 2015

Published online: 03 May 2015

\section{References}

1. The United Nations Office on Drugs and Crime. World Drug Report 2014 2014. Available from: http://www.unodc.org/wdr2014/.

2. National Institues on Drug Abuse. Popping Pills: Prescription Drug Abuse in America. Available from: http://www.drugabuse.gov/related-topics/ trends-statistics/infographics/popping-pills-prescription-drug-abuse-in-america\#1.

3. Jones $\mathrm{CM}$. Heroin use and heroin use risk behaviors among nonmedical users of prescription opioid pain relievers-United States, 2002-2004 and 2008-2010. Drug Alcohol Depend. 2013;132(1):95-100.

4. Ling W, Hillhouse M, Ang A, Jenkins J, Fahey J. Comparison of behavioral treatment conditions in buprenorphine maintenance. Addiction. 2013;108(10):1788-98. 
5. Mattick RP, Breen C, Kimber J, Davoli M. Buprenorphine maintenance versus placebo or methadone maintenance for opioid dependence. Cochrane Library. 2014.

6. Marsch LA. The efficacy of methadone maintenance interventions in reducing illicit opiate use, HIV risk behavior and criminality: a meta-analysis. Addiction. 1998;93(4):515-32.

7. Connock M, Juarez-Garcia A, Jowett S, Frew E, Liu Z, Taylor R, et al. Methadone and buprenorphine for the management of opioid dependence: a systematic review and economic evaluation. 2007.

8. Weiss RD, Potter JS, Fiellin DA, Byrne M, Connery HS, Dickinson W, et al. Adjunctive counseling during brief and extended buprenorphine-naloxone treatment for prescription opioid dependence: a 2-phase randomized controlled trial. Arch Gen Psychiatry. 2011;68(12):1238-46.

9. Peterson JA, Schwartz RP, Mitchell SG, Reisinger HS, Kelly SM, O'Grady KE, et al. Why don't out-of-treatment individuals enter methadone treatment programmes? Int J Drug Policy. 2010;21(1):36-42.

10. Johnson RE, Chutuape MA, Strain EC, Walsh SL, Stitzer ML, Bigelow GE. A comparison of levomethadyl acetate, buprenorphine, and methadone for opioid dependence. N Engl J Med. 2000;343(18):1290-7.

11. Strain EC, Bigelow GE, Liebson IA, Stitzer ML. Moderate-vs high-dose methadone in the treatment of opioid dependence: a randomized trial. JAMA. 1999;281(11):1000-5.

12. Ling W, Wesson DR, Charuvastra C, Klett CJ. A controlled trial comparing buprenorphine and methadone maintenance in opioid dependence. Arch Gen Psychiatry. 1996;53(5):401-7.

13. Comer SD, Sullivan MA, Hulse GK. Sustained-release naltrexone: novel treatment for opioid dependence. 2007.

14. Minozzi S, Amato L, Vecchi S, Davoli M, Kirchmayer U, Verster A. Oral naltrexone maintenance treatment for opioid dependence. Cochrane Library. 2011.

15. Comer SD, Sullivan MA, Yu E, Rothenberg JL, Kleber HD, Kampman K, et al. Injectable, sustained-release naltrexone for the treatment of opioid dependence: a randomized, placebo-controlled trial. Arch Gen Psychiatry. 2006;63(2):210-8.

16. Krupitsky E, Nunes EV, Ling W, Illeperuma A, Gastfriend DR, Silverman BL. Injectable extended-release naltrexone for opioid dependence: a double-blind, placebo-controlled, multicentre randomised trial. Lancet. 2011;377(9776):1506-13.

17. Krupitsky EM, Blokhina EA. Long-acting depot formulations of naltrexone for heroin dependence: a review. Curr Opin Psychiatry. 2010;23(3):210-4.

18. Ling W, Mooney L, Wu L-T. Advances in opioid antagonist treatment for opioid addiction. Psychiatr Clin N Am. 2012;35(2):297-308.

19. Strathdee SA, Patrick DM, Currie SL, Cornelisse PG, Rekart ML, Montaner JS, et al. Needle exchange is not enough: lessons from the Vancouver injecting drug use study. AIDS. 1997;11(8):F59-65.

20. Tyndall MW, Currie S, Spittal P, Li K, Wood E, O'Shaughnessy MV, et al. Intensive injection cocaine use as the primary risk factor in the Vancouver HIV-1 epidemic. AIDS. 2003;17(6):887-93.

21. Hadland SE, Marshall BD, Kerr T, Zhang R, Montaner JS, Wood E. A comparison of drug use and risk behavior profiles among younger and older street youth. Subst Use Misuse. 2011;46(12):1486-94.

22. Kerr T, Marshall BD, Miller C, Shannon K, Zhang R, Montaner JS, et al. Injection drug use among street-involved youth in a Canadian setting. BMC Public Health. 2009;9:171.

23. Fitzgerald JP, McCarty D. Understanding attitudes towards use of medication in substance abuse treatment: A multilevel approach. Psychol Serv. 2009;6(1):74-84.

24. Fuller BE, Rieckmann T, McCarty D, Smith KW, Levine H. Adoption of naltrexone to treat alcohol dependence. J Subst Abus Treat. 2005;28(3):273-80.

25. Thomas CP, Wallack SS, Lee S, McCarty D, Swift R. Research to practice: adoption of naltrexone in alcoholism treatment. J Subst Abus Treat. 2003;24(1):1-11.

26. Kerr T, Marsh D, Li K, Montaner J, Wood E. Factors associated with methadone maintenance therapy use among a cohort of polysubstance using injection drug users in Vancouver. Drug Alcohol Depend. 2005;80(3):329-35.

27. Garfein RS, Swartzendruber A, Ouellet $\sqcup$, Kapadia F, Hudson SM, Thiede H, et al. Methods to recruit and retain a cohort of young-adult injection drug users for the Third Collaborative Injection Drug Users Study/Drug Users Intervention Trial (CIDUS III/DUIT). Drug Alcohol Depend. 2007;91(Supplement 1):S4-17.
28. Rotondi NK, Strike C, Kolla G, Rotondi MA, Rudzinski K, Guimond T, et al. Transition to injection drug use: the role of initiators. AIDS Behav. 2014;18(3):486-94.

29. Chen YH, McFarland W, Raymond HF. Risk behaviors for HIV in sexual partnerships of San Francisco injection drug users, AIDS Care. 2013.

30. Palepu A, Marshall BD, Lai C, Wood E, Kerr T. Addiction treatment and stable housing among a cohort of injection drug users. PLoS One. 2010;5(7), e11697.

31. Abuse NloD. Comparing Treatments for HIV-Positive Opioid Users in an Integrated Care Effectiveness Study (CHOICES) 2014 [cited 2014 August 18, 2014]. Available from: http://www.drugabuse.gov/about-nida/organization/ $\mathrm{cctn/ctn/research-studies/comparing-treatments-hiv-positive-opioid-users-in-in-}$ tegrated-care-effective.

32. Des Jarlais DC, Paone D, Milliken J, Turner CF, Miller H, Gribble J, et al. Audio-computer interviewing to measure risk behaviour for HIV among injecting drug users: a quasi-randomised trial. Lancet. 1999;353(9165):1657-61.

\section{Submit your next manuscript to BioMed Central and take full advantage of:}

- Convenient online submission

- Thorough peer review

- No space constraints or color figure charges

- Immediate publication on acceptance

- Inclusion in PubMed, CAS, Scopus and Google Scholar

- Research which is freely available for redistribution 